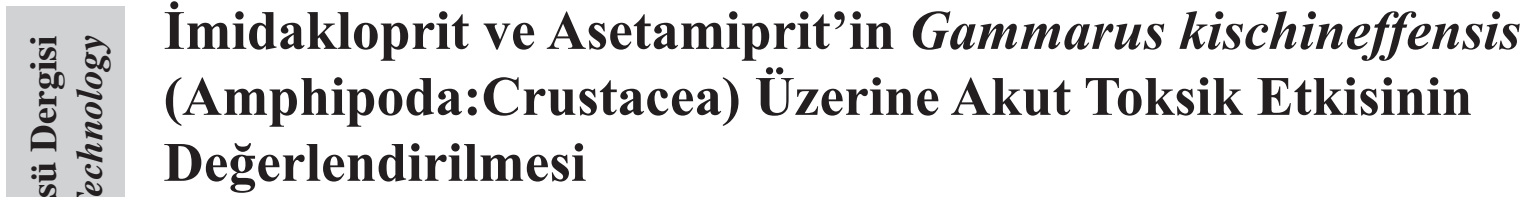

Özlem DEMIRCI ${ }^{1}$

ÖZET: Bu çalışmada, önemli bir organik ksenobiyotik sınıfı olan neonikotinoit pestisitlerden asetamiprit ve imidakloprit'in Gammarus kischineffensis üzerine akut toksik etkisini araştırmak üzere, 48, 72 ve 96 saatlik $\mathrm{LC}_{50}$ değerleri belirlenmeye çalışılmıştır. Kullanılan doz aralığında; asetamiprit için $\mathrm{LC}_{50}$ değeri 72 ve 96 saat için sırasıyla 1.687 ve $0.517 \mu \mathrm{g} \mathrm{L}{ }^{-1}$; imdakloprit için 48,72 ve 96 saatteki $\mathrm{LC}_{50}$ değeri $9764.4,4546.7$ ve $1560.9 \mu \mathrm{g} \mathrm{L}^{-1}$ olarak belirlenmiştir.

Anahtar Kelimeler: Asetamiprit, imidakloprit, akut toksisite, Gammarus kischineffensis, $\mathrm{LC}_{50}$.

\section{The Evaluation of Acute Toxic Effect of Imidacloprid and Acetamiprid on Gammarus kischineffensis (Amphipoda: Crustacea)}

ABSTRACT: In this study, 48, 72 and 96 hours $\mathrm{LC}_{50}$ values were determined in order to investigate the acute toxic effect of acetamiprite and imidaclopride on Gammarus kischineffensis from neonicotinoid pesticides, an important class of organic xenobiotics. At the dose interval used; $\mathrm{LC}_{50}$ value for acetamiprid was 1.687 and $0.517 \mu \mathrm{g} \mathrm{L}^{-1}$ for 72 and 96 hours, respectively; $\mathrm{LC}_{50}$ values at 48, 72 and 96 hours for imdacloprid were determined as $9764.4,4546.7$ and $1560.9 \mu \mathrm{g} \mathrm{L}^{-1}$.

Keywords: Acetamiprid, imidacloprid, acute toxicity, Gammarus kischineffensis, $\mathrm{LC}_{50}$.

Özlem DEMİRCI (0000-0001-9511-2010), Dicle Üniversitesi, Fen Fakültesi, Biyoloji, Diyarbakır, Türkiye Sorumlu yazar/Corresponding Author: Özlem DEMIRCI, ozdem22@gmail.com 


\section{GİRIȘ}

Kimyasalların neden olduğu kirlilik için çevresel risk değerlendirmesi genellikle standart test organizmaları ile yapılan toksisite testlerine dayanmaktadır (van Leeuwen and Vermeire, 2007). Akut toksisite testleri, belirli bir sürede organizmaların \%50 ölümüne $\left(\mathrm{LC}_{50}\right)$ neden olan maruz kalma konsantrasyonunun belirlenmesini sağlar. Bunun yanında sıklıkla kullanılan etkili konsantrasyonu $\left(\mathrm{EC}_{50}\right)$, organizmanın hareketsizliğine veya tanımlanabilir başka bir özelliğine dayanır. Ortalama Öldürücü Konsantrasyon $\left(\mathrm{LC}_{50}\right)$ uygulamas1, toksikologlar arasında kabul görmüş ve genellikle kimyasal kirleticilerin sudaki yaşama olumsuz etkilerini değerlendirmede çok yükssek oranda test edilmiştir (Johnson and Finley, 1980).

Nikotinik pestisitler, üç farklı jenerasyona sahiptirler. Öncelikle organofosfor bileşikleri daha sonra nitrometilen türü bileşikler ve nihayetinde neotikotinoitler piyasaya sürülmüştür. Sentetik nikotinoitler son 40 yılda piyasaya sunulan en büyük böcek öldürücü sınıfıdır. Nörotransmitter reseptörleri hem omurgalılarda hem de omurgasız hayvanlarda ilk olarak nikotinik asetilkolin reseptörleri (nAChR'leri) tarafindan uyarılır. Böceklerde nAChR'leri, karakteristik böcek öldürücü özelliğe sahip çeşitli doğal ve sentetik bileşiklerin hedef bölgesi konumundadır (Millar and Denholm, 2007). Neonikotinoitlerin, memelilerin ve böceklerin nAChR'leri arasındaki temel ayrışmadan ötürü önemli seçicilik sağladığı düşünülmektedir (Tomizawa and Casida 2003). Fakat yapılan çalışmalar hedef olmayan organizmalar üzerinde de toksik etkisi olduğunu göstermiştir (Iwasa et al., 2004; Kocaman ve Topaktaş, 2007; Beketov and Liess, 2008; Mishchuk and Stoliar, 2008; Demirci ve ark., 2015; Raj and Joseph, 2015).

İmidakloprit en çok satılan yeninesil insektisitlerden biridir. İmidakloprit, geleneksel kimyasallara dirençli türler de dahil olmak üzere yaprak bitleri, leafhoppers ve plantopper, kirpikkanatlllar ve beyaz sinekler gibi emici böcekler için primer aktiviteye sahip, sistemik bir insektisitdir (Mullins, 1993).

Asetamiprid meyve ağaçlarının, sebzelerin, çay ağacının ve benzeri zararlıların kontrolünde kullanılan geniş spektrumlu bir insektisittir. $\mathrm{Bu}$ nedenle asetamiprid yaygın olarak tarımda değil, aynı zamanda evsel alanlarda da çok çeşitli zararlılara karşı kullanılmaktadır (Yamamoto, 1999).
Geniş spektrumlu bir insektisit olduğu için, böcek öldürücülerin uygulanması gereken standart konsantrasyon dozlarından daha fazlası bilerek ve bilmeden çiftçiler ve diğer kullanıcılar tarafından daha etkili sonuçlar almak için kullanılır. Bu nedenle sucul alanlara girer ve tatlı su organizmalarının morfolojisi, fizyolojisi ve davranışı üzerinde etkili olabilir (Siddiqui and Wanule, 2010). Asetamiprit için herhangi bir sinırlama olmamasına rağmen bazı neonikotinoitlerin kullanımı AB komisyonu tarafindan kısıtlanmıştır. İmidakloprit de bu insektisitleden biridir (Ojeu, 2013).

Toksisite nedeni ile büyük omurgasız hayvanların sayılarındaki azalma ekolojik olarak çok iyi bilinen bir olgudur. Bununla birlikte hangi maddelerin buna hangi ölçüde neden olacağı daha az bilinmektedir (Beketov and Liess 2008). Gammaridler tatlı sularda oldukça yaygın olarak dağılım gösteren ve bentik bölgede büyük omurgasızların büyük çoğunluğunu oluşturan türler olup, hem etobur hem de otoburdur olarak beslenirler (MacNeil et al., 1997).

Gammarid türleri, hem deniz hem de tatlı sular için önemli biyogösterge canlılarıdır (Woods et al., 2002; Gerhardt et al., 2011). Dahası, çevre toksikolojisi alanında memelilerin kullanıldığı çalışmalardaki kısıtlamalar nedeniyle Gammarus gibi bir çok amfipod omurgasız hayvanlar son zamanlarda daha fazla ilgi çekmektedir (Kandárová and Letašiová, 2011). Yapılan son çalışmalarda Gammarus kischineffensis test organizması olarak kullanılmıştır (Demirci ve ark., 2015; Uğurlu ve ark., 2015).

$\mathrm{Bu}$ çalışmanın amacı yeni nesil pestisitler olan neonikotinoitlerden imidakloprit ve asetamipritin G. kischineffensis üzerine akut toksik etkisinin belirlenmesidir.

\section{MATERYAL VE YÖNTEM}

\section{Kullanılan Kimyasallar}

Çalışmada kullanılan pestisitler \% 20 asetamiprit aktif maddesi içeren Hekplan ${ }^{\circledR} 20 \mathrm{SP}$ ve litrede $350 \mathrm{mg}$ imidakloprit aktif maddesi içeren Confidor $^{\circledR}$ SC 350 yerel bir tarım ilacı bayisinden temin edilmiştir. 


\section{Kullanılan Canlıların Toplanması ve Adaptas- yonu}

Çalışmada kullanılan G. kischineffensis örnekleri, Dicle Üniversitesi kampüsündeki temiz bir su kaynağının yavaş akışlı bölgesinden yapraklar ve taşların altından uzun elekler ve daldırma ağları ile toplanmıştır. $\mathrm{Bu}$ çalışmada kullanılan Gammarus kischineffensis Schellenberg 1937 türü Prof. Dr. Murat ÖZBEK tarafından teşhis edilmiştir. Laboratuvara getirilirken hasar görmemiş ve aktif bireyler, araziden getirilen su ve laboratuvarda önceden hazırlanmış deklorize musluk suyu ile 50:50 oranında karıştırılarak hazırlanan karışımı içeren, 40x35x40 cm büyüklüğündeki cam akvaryumlara yerleştirilmiştir. Her akvaryuma hava taşlarıyla havalandırılmış çeşme suyuyla akvaryum suyunun yaklaşık \% 50'si günlük olarak deklorize musluk suyu ile değiştirilmiştir. Canlıların bulunduğu kontrollü oda hem adaptasyon süresi hem de deneyler sirasında, sıcaklık $18 \pm 1{ }^{\circ} \mathrm{C}$ ve yapay 1şık rejimi 13 saat 1 şı: 12 saat karanlık olacak şekilde tutulmuştur. Akvaryumlardaki suların bazı ortalama değerleri; sicaklık $16.8 \pm 0.32^{\circ} \mathrm{C}, \mathrm{pH} 8,5 \pm 0.04$ ve çözünmüş oksijen miktarı $9.0 \pm 0.09 \mathrm{mg} \mathrm{L}^{-1}$ olarak ölçülmüş̧ür. Hayvanların deneylere başlamadan önce (adaptasyon süreci) doğal yaşam alanlarından toplanan sögüt (Salix sp.) yaprakları ile en az 2 hafta süre ile beslenmiştir (Cold and Forbes, 2004).

\section{Akut Toksisite Deneyleri}

Akut toksisite testlerinde prekopülasyon yapacak olgunluğa erişmiş $G$. kischineffensis örnekleri kullanılmıştır. Akut toksisite testi, yarı-statik yenileme yapılan test koşulları altında gerçekleştirilmiştir (Federation and Association, 2005). Akut toksisite testinde kullanılacak olan çözeltiler, asetamiprit ve imidakloprit aktif maddelerini içeren ticari pestisitler kullanılarak hazırlanmıştır. Test edilen imidakloprit aktif maddesinin nominal konsantrasyonları 0 (kontrol), 400, 600, 900, 1350, 2025, 3040, 4556, 6834, 10251, $15376 \mu \mathrm{g} \mathrm{L}^{-1}$, asetamiprit aktif maddesi için nominal konsantrasyonlar ise 0 (kontrol), 10, 17, 29, 49, 84, 142, 241, 410, 615, 922, 1384, 2075, 3113, $4670 \mu \mathrm{g} \mathrm{\textrm {L } ^ { - 1 }}$ olarak düzenlenmiştir. Dozlar belirlenirken öncelikle literatürden yola çıkılmış ve aralık belirleme deneyleri yapılmıştır. Tüm deneylerde 2 L'lik cam kaplara 10 birey konulmuş ve deneyler 3 tekrarlı olarak gerçekleştirilmiştir. Yarı-statik yenileme yapılarak testler boyunca her 24 saatte bir canliların bulunduğu kapların içindeki test solüsyonun yarısı taze hazırlanmış aynı miktarda pestisit içeren solüsyonlar ile değiştirilmiş ve canlılar 96 saat boyunca maruz bırakmıştır. Asetamiprit ve imidakloprite maruz kaldıktan sonra canlıların ölüm oranları, 0, 24, 48, 72 ve 96 saat boyunca kaydedilmiştir. Vücutları hareketsiz olan ve ölüm sertliği gözlenen bireyler ölü olarak kabul edilmiştir (Anderson 1982, Cold and Forbes, 2004).

\section{İstatistiksel Analiz}

İstatistiksel analiz yapılırken $\mathrm{LC}_{50}$ değerleri SPSS programinda (versiyon 1.5) probit analiz ile hesaplanmış ve testlerde anlamlılık düzeyi $\mathrm{p}<0.05$ olarak kabul edilmiştir.

\section{BULGULAR VE TARTIŞMA}

Değişen kimyasal konsantrasyonlarının risk değerlendirmesi için kullanılabilecek modeller geliştirmek için Gammarus türleri kullanılmaktadır (Ashauer et al., 2007; Beketov and Liess 2008).

Yapılan bu çalışmada yüksek konsantrasyonlarda imidakloprit ve asetamiprit insektisitlerine maruz kalan G. kischineffensis türüne ait bireylerde prekopulasyon davranışında bozulma gözlenmiştir. Davranışsal yanitlar, biyokimyasal ve fizyolojik yanitlar kadar benzer duyarlılık ve verimlilikte görünmektedir ve bu yanıtların dayanıklılığı ve sürekli nedeni ile uzun vadeli izlenebilmesi mümkündür (Gerhardt et al., 2007). Gammarus türleri, ekotoksikolojik araştırmalarda değerli olan karmaşık bir yaşam döngüsüne sahiptirler. Çünkü çiftleşme davranışındaki değişiklikler (prekopulasyon) ksenobiyotik madde maruziyetinde daha kolay gözlemlenebilir (Poulton and Pascoe, 1990; Watts et al., 2001). Gammarus türlerinin çevresel kirleticilere maruz kalmasının ardından ilk olarak beslenme aktivitesinde bozukluklar gözlenmektedir. Gammarus gibi ölü organik maddeler ve bitki döküntüleriyle beslenen canlıların toksik etkiye maruz kalması bu döküntülerin tatlı sulardaki artışına neden olmaktadır (Kunz et al., 2010).

Hem asetamiprit hem de imidaklopritin $\mathrm{LC}_{50}$ değerleri belirlenirken kontrol gruplarında ölüm gözlenmemiş ve imidaklopritin $6834 \mu \mathrm{g} \quad \mathrm{L}^{-1}$ lik konsantrasyonu dışındaki tüm uygulamalarda konsantrasyon artışına bağlı olarak \% ölüm artmıştır (Çizelge 1 ve Çizelge 2). 
Çizelge 1. Asetamipritin farklı konsantrasyonlarına maruz kalan G. kischineffensis için \% ölüm oranları

\begin{tabular}{lcccc}
\hline Konsantrasyon & \multicolumn{3}{c}{ Ölüm Oranı \% } \\
\hline$\left.(\mu \mathrm{g} \mathrm{L})^{-1}\right)$ & 24 & 48 & 72 & 96 \\
0.01 & 0 & 0 & 5 & 15 \\
0.017 & 10 & 10 & 10 & 25 \\
0.029 & 10 & 10 & 20 & 30 \\
0.049 & 5 & 15 & 30 & 35 \\
0.084 & 25 & 25 & 35 & 45 \\
0.142 & 15 & 25 & 30 & 35 \\
0.241 & 20 & 25 & 25 & 30 \\
0.410 & 10 & 20 & 25 & 30 \\
0.615 & 0 & 15 & 25 & 30 \\
0.922 & 15 & 20 & 35 & 50 \\
1.384 & 10 & 30 & 50 & 60 \\
2.075 & 10 & 20 & 55 & 70 \\
3.113 & 10 & 15 & 60 & 70 \\
4.670 & 45 & 45 & 70 & 90 \\
\hline
\end{tabular}

Çizelge 2. İmidaklopritin farklı konsantrasyonlarına maruz kalan G. kischineffensis için \% ölüm oranları

\begin{tabular}{lcccc}
\hline Konsantrasyon & \multicolumn{3}{c}{ Ölüm Oranı \% } \\
\hline$\left(\mu \mathrm{g} \mathrm{L}^{-1}\right)$ & 24 & 48 & 72 & 96 \\
400 & 0 & 10 & 10 & 15 \\
600 & 10 & 10 & 15 & 20 \\
900 & 5 & 10 & 25 & 40 \\
1350 & 10 & 15 & 30 & 50 \\
2025 & 15 & 30 & 45 & 60 \\
3040 & 15 & 20 & 35 & 65 \\
4556 & 20 & 35 & 60 & 80 \\
6834 & 27 & 42 & 54 & 72 \\
10251 & 40 & 50 & 60 & 95 \\
15376 & 50 & 60 & 65 & 95 \\
\hline
\end{tabular}

Bu araştırmada neonikotinoit pestisitler olan asetamiprit ve imidaklopritin akut toksik etkisi incelenmiş ve asetamiprit için 72 saatlik $\mathrm{LC}_{50}$ değeri $1.687 \mu \mathrm{g} \mathrm{L}^{-1}$ ve 96 saatlik $\mathrm{LC}_{50}$ değeri ise 0.517. $\mu \mathrm{g} \mathrm{L} \mathrm{L}^{-1}$ olarak tespit edilmiştir (Çizelge 3).

Çizelge 3. G. kischineffensis için Ortalama Öldürücü Konsantrasyon $\left(\mathrm{LC}_{50}\right)$ değerleri

\begin{tabular}{|c|c|c|c|c|c|c|}
\hline & \multirow{2}{*}{$\begin{array}{l}\text { Nominal Test } \\
\text { aralığı }\end{array}$} & \multirow{2}{*}{$\begin{array}{l}\text { Birey } \\
\text { sayısı }\end{array}$} & \multicolumn{4}{|c|}{$\mathrm{LC}_{50}\left(\mu \mathrm{g} \mathrm{L}^{-1}\right)$} \\
\hline & & & 24 saat & 48 saat & 72 saat & 96 saat \\
\hline Asetamiprit & $0.01-4.670$ & 10 & do. & d.o. & $\begin{array}{l}1.687 \\
(0.830-5.279)\end{array}$ & $\begin{array}{l}0.517 \\
(0.277-1.152)\end{array}$ \\
\hline İmidakloprit & $400-15376$ & 10 & d.o. & $\begin{array}{l}9764.4 \\
(6154-21845)\end{array}$ & $\begin{array}{l}4546.7 \\
(3035-7725)\end{array}$ & $\begin{array}{l}1560.9 \\
(1136-2046)\end{array}$ \\
\hline
\end{tabular}

d.o. $=$ Denene konsantrasyon aralığında olmayan değer

$\mathrm{LC}_{50}$ değerleri $95 \%$ güven aralığındadır $(\mathrm{p}<0.05)$ 
Beketov and Liess (2008) tarafindan yapilan çalışmada Gammarus pulex için asetamiprit analitik standardının 96 saatlik $\mathrm{LC}_{50}$ değeri $50.0 \mu \mathrm{g} \mathrm{L}^{-1}$ olarak bulunmuştur. Englertetal.,(2017) ise asetamipritin ticari formuna maruz bırakılan Gammarus fossarum türünün bireylerinin 7 günlük $\mathrm{LC}_{20}$ değerini $21.34 \mu \mathrm{g} \mathrm{L}^{-1}$ olarak saptamışlardır (Çizelge 4). Yaptı̆̆ımız çalışmada elde edilen $\mathrm{LC}_{50}$ değeri diğer çalışmalar karşılaştırıldığında oldukça düşük bulunmuştur. Asetamiprit ile yapılan daha önceki çalışmalarda hem analitik standart hem de ticari formlar kullanılmıştır. Bu önemli düzeydeki fark kullanılan pestisitin ticari olmasından kaynaklanabilir. Englert et al., (2017) tarafından yapılan çalışmada da ticari bir pestisit kullanılmakla birlikte farklı bir firma tarafından üretilmiş̧ir. $\mathrm{Bu}$ sonuçlar asetamiprit ile birlikte ticari pestisit içeriğinde bulunan kimyasalların farklı düzeyde toksik etkiye neden olduğunu gösterebilir.

Çizelge 4. Farklı zamanlarda asetamiprite maruz kalan Gammarus türlerinin $\mathrm{LC}_{20}-\mathrm{LC}_{50}$ değerleri

\begin{tabular}{lllll}
\hline Tür ismi & Maruz kalma süresi & $\mathbf{L C}_{\mathbf{2 0}} \mathbf{L C}_{\mathbf{5 0}}$ & Konsantrasyon & Kaynak \\
\hline$*$ Gammarus fossarum & 7 gün & $\mathrm{LC}_{20}$ & $21.34 \mu \mathrm{g} \mathrm{L}^{-1}$ & (Englert et al., 2017) \\
$* *$ Gammarus fossarum & 7 gün & $\mathrm{LC}_{20}$ & $328.62 \mu \mathrm{g} \mathrm{L}^{-1}$ & (Engle et al., 2017) \\
Gammarus pulex & 96 saat & $\mathrm{LC}_{50}$ & $50.0 \mu \mathrm{g} \mathrm{L}^{-1}$ & (Beketov and Liess 2008) \\
\hline
\end{tabular}

*Hem ortama hem de besine pestisit uygulanması sonucunda elde edilmiştir

**Sadece ortama pestisit eklenerek maruz bırakma sonucunda elde edilmiştir

Başka bir krustase olan Daphnia magna için 48 saatlik $\mathrm{LC}_{50}$ değeri $10.44 \mathrm{mg} \mathrm{L}^{-1}$ olarak bulunmuştur (Song et al., 1997). Bu çalışmanın sonuçları, $G$. kischineffensis'in $G$. pulex' e göre daha az, $D$. magna'ya göre ise daha fazla hassas olduğunu ortaya koymuştur. Literatürde Gammarus türlerinin asetamiprite maruziyeti ile ilgili başka bir çalışmaya rastlanmamıştır. Asetamiprit ile yapılan çalışmaların az sayıda olması ve asetamipritin yaygın olarak kullanılan bir insektisit olması nedeniyle bu çalışmanın önemli bir katkı sunduğu düşünülmektedir.

İmidakloprit için ise 48 saatlik $\mathrm{LC}_{50}$ değeri 9764.4 $\mu \mathrm{g} \mathrm{L}{ }^{-1}, 72$ saatlik $\mathrm{LC}_{50}$ değeri $4546.7 \mu \mathrm{g} \mathrm{L}^{-1}$ ve 96 saatlik $\mathrm{LC}_{50}$ değeri ise $1560.9 \mu \mathrm{g} \mathrm{\textrm {L } ^ { - 1 }}$ olarak belirlenmiştir (Çizelge 3). Ashauer et al., (2010) imidakloprite maruz kalan Gammarus pulex için 24 saatlik $\mathrm{LC}_{10}$ değerini $582 \mu \mathrm{g} \mathrm{L}^{-1}, \mathrm{LC}_{50}$ değerini ise $8760 \mu \mathrm{g} \mathrm{L}^{-1}$ olarak belirlemişlerdir. Berketov et al., (2008)'e göre G. pulex için 96 saatlik $\mathrm{LC}_{50}$ değeri $270 \mu \mathrm{g} \mathrm{L}^{-1}$, van den Brink et al., (2016)'ya göre $386 \mu \mathrm{g} \mathrm{L}^{-1}$, Roessink et al., (2013) göre ise $263 \mu \mathrm{L}^{-1}$ 'dir (Çizelge 5). Bu çalışmaların tümünde imidaklopritin analitik standard formu kullanılmıştır. Başka bir crustacea olan Daphnia magna için 48 saatlik $\mathrm{LC}_{50}$ değeri $10.44 \mathrm{mg} \mathrm{L}^{-1}$ olarak bulunmuştur (Song et al., 1997). Bu çalışmada imidakloprit için elde edilen $\mathrm{LC}_{50}$ değerleri ile literatürde G. pulex ve G. fossarum için verilen değerler önemli farklar göstermektedir.
Aynı türler ya da farklı Gammarus türleri arasındaki $\mathrm{LC}_{50}$ değerlerindeki oldukça geniş varyasyon dikkati çekmektedir. Bu tür farklılıklar, deneylerde kullanılan suyun fiziko-kimyasal özellikleri, birey hacmi ve diğer ortam farklılıklarından kaynaklanabilmektedir (Fisher, 1991; Dietrich et al., 2014). Daha önce yapılan çalışmalarda analitik standart kullanılmış olmasına rağmen yaptığımız çalışmada asetamiprit gibi imidakloprit uygulamasında da pestisitin ticari formu kullanılmıştır.

Literatürdeki sonuçlarla yaptığımız çalışma arasındaki önemli düzeydeki farkın ticari formda bulunan diğer maddelerden kaynaklandığı düşünülebilir. Kombinasyon halindeki maddeler canlılar üzerinde sinerjistik veya antagonistik etkiye neden olabilmektedir (Folt et al.,1999). Pereira et al., (2009) yaptıkları çalışmada üç farklı pestisitin (Glifosat, propanil ve metilomil) hem analitik standartlarının hem de ticari formlarının Daphnia magna üzerine etkisini incelemiş ve glifosat'in standardına maruz kalan canlılarda $\mathrm{EC}_{50}$ değerleri 2000 mg L-1'den fazla iken $350 \mathrm{mg} \mathrm{L}^{-1}$ 'dir fakat diğer pestisitler için elde edilen $\mathrm{EC}_{50}$ sonuçlarında bu düzeyde fark gözlenmemiştir. Literatürde neonikotinoitlerin ticari ve standart formlarının karşılaştırıldığ 1 çok fazla çalışma bulunmamasına rağmen Uğurlu et al., (2015) tarafindan yapılan çalışmada tiametoksamın ticari formunun $G$. kischineffensis için 96 saatlik $\mathrm{LC}_{50}$ değerini $3.751 \mathrm{mg} \mathrm{L}^{-1}$ 
olarak, Demirci et al., (2018) tarafindan yapılan ve thiametoksamın analitik standartının kullanıldığı bir diğer çalışmada ise 96 saatlik $\mathrm{LC}_{50}$ değerinin $8.9 \mathrm{mg} \mathrm{L}^{-1}$ olduğu tespit edilmiştir. Bir maddenin kimyasal özellikleri neden olduğu toksisite ile yakından ilişkilidir. Yapılan çalışmalarda Log $\mathrm{K}_{\text {ow }}$ (oktanol-su ayrılım katsayısı) ve moleküler ağılık gibi özelliklerin biyolojik birikim ve toksisite ile bağlantılı olduğu ortaya konulmuştur (Hodson et al., 1988; DeLorenzo et al., 2002). İmidakloprit ve asetamiprit için $\log \mathrm{K}_{\text {ow }}$ değeri sırasıyla 0.57 ve
0.8 olarak bulunmuştur. Her iki pestisitte düşük yağda çözünme oranına sahiptir fakat G. kischineffensis için 96 saatlik $\mathrm{LC}_{50}$ değeri oldukça farklıdır (Hoffmann, 2008). Çalışmamızda kullandığımız pestisitler ticari formlar olduğu için analitik standartlar dışında farklı maddeler içermektedir. Bu nedenle ticari pestisitlerin içerdikleri maddelerin kombine etkilerinin, imidakloprit ve asetamipritin analitik standartlarının kimyasal özellikleri ile açıklanması oldukça zordur.

Çizelge 5. Farklı zamanlarda imidakloprite maruz kalan Gammarus türlerinin $\mathrm{LC}_{10}-\mathrm{LC}_{50}$ değerleri

\begin{tabular}{lllll}
\hline Tür İsmi & Maruz Kalma Süresi & $\mathbf{L C}_{\mathbf{2 0}}-\mathbf{L C}_{\mathbf{5 0}}$ & Konsantrasyon & Kaynak \\
\hline Gammarus pulex & 24 saat & $\mathrm{LC}_{10}$ & $582 \mu \mathrm{g} \mathrm{L}^{-1}$ & (Ashauer et al., 2010) \\
Gammarus pulex & 48 saat & $\mathrm{LC}_{10}$ & $220 \mu \mathrm{g} \mathrm{L}^{-1}$ & (Ashauer et al., 2010) \\
Gammarus pulex & 96 saat & $\mathrm{LC}_{10}$ & $64 \mu \mathrm{g} \mathrm{L}^{-1}$ & (Van den Brink et al., 2016) \\
Gammarus pulex & 96 saat & $\mathrm{LC}_{10}$ & $99.5 \mu \mathrm{g} \mathrm{L}^{-1}$ & (Roessink et al., 2013) \\
Gammarus pulex & 28 gün & $\mathrm{LC}_{10}$ & $5.77 \mu \mathrm{g} \mathrm{L}^{-1}$ & (Roessink et al., 2013) \\
Gammarus pulex & 24 saat & $\mathrm{LC}_{50}$ & $8760 \mu \mathrm{g} \mathrm{L}^{-1}$ & (Ashauer et al., 2010) \\
Gammarus pulex & 48 saat & $\mathrm{LC}_{50}$ & $3857 \mu \mathrm{g} \mathrm{L}^{-1}$ & (Ashauer et al., 2010) \\
Gammarus fossarum & 48 saat & $\mathrm{LC}_{50}$ & $800 \mu \mathrm{g} \mathrm{L}^{-1}$ & (Lukančič et al., 2010) \\
Gammarus fossarum & 48 saat & $\mathrm{LC}_{50}$ & $70 \mu \mathrm{g} \mathrm{L}^{-1}$ & (Lukančič et al., 2010) \\
Gammarus pulex & 96 saat & $\mathrm{LC}_{50}$ & $270 \mu \mathrm{g} \mathrm{L}^{-1}$ & (Beketov and Liess 2008) \\
Gammarus pulex & 96 saat & $\mathrm{LC}_{50}$ & $386 \mu \mathrm{g} \mathrm{L}^{-1}$ & (Van den Brink et al., 2016) \\
Gammarus pulex & 96 saat & $\mathrm{LC}_{50}$ & $263 \mu \mathrm{g} \mathrm{L}^{-1}$ & (Roessink et al., 2013) \\
Gammarus pulex & 28 gün & $\mathrm{LC}_{50}$ & $33.8 \mu \mathrm{g} \mathrm{L}^{-1}$ & (Roessink et al., 2013) \\
\hline
\end{tabular}

EPA tarafından pestisitler için yapılan toksisite sınıflandırmasına göre çalışmamızda elde ettiğimiz asetamiprit için 96 saatlik $\mathrm{LC}_{50}$ değerleri $<0.1$ ppm olduğu için çok yüksek toksik iken imidakloprit için 96 saatlik LC $_{50}$ değerleri 1lımlı toksiktir (>1-10 ppm) (US EPA, 2017).

Bununla birlikte imidakloprit gibi pek çok neonikotinoit AB komisyonu tarafindan yasaklanmasına rağmen asetamiprit yasaklı bir pestisit değildir (Ojeu, 2013; US EPA, 2017). Özellikle neonikotinoitlerin arılar üzerindeki toksik etkileri ile ilgili pek çok çalışma mevcuttur (Blacquiere et al., 2012; Whitehorn et al., 2012 Decourtye and Devillers, 2010). AB komisyonu kararlarında daha çok neonikotinoitlerin arılar üzerindeki etkisinin dikkate alındığ (EU Commision, 2018). Fakat literatürdeki diğer çalışmalar ve yaptığımız çalışma sonuçlarına göre; imidakloprit ile karşılaştırıldığında asetamipritin sucul büyük omurgasız hayvanlar üzerinde önemli düzeyde toksik etkiye sahiptir. Bu alandaki çalışmaların artması neonikotinoitlerin farklı canlı grupları üzerindeki etkisini daha gerçekçi bir şekilde ortaya koyacaktır.

Neonikotinoitler, doğal toksin nikotinden türetilmiş yeni bir kimyasal böcek öldürücü sınıfıdır. 1990'ların başında pazara sunulan ilk bileşik olan imidakloprit, organoklorinler ve organofosfatlar gibi daha eski insektisitlerin neden olduğu çevresel sorunların çözümü olarak düşünülmüştür (Sánchez et al., 2016). Fakat daha sonra yapılan çalışmalarda hedef olmayan organizmalar için zararlı olduğunu gösteren akut toksisitesi ortaya konulmuştur (Beketov and Liess 2008; Ashauer et 
al., 2011; Englert et al., 2017). Ayrica Ashauer et al., (2011) tarafından yapılan çalışmada imidakloprite maruz kalan G. pulex'in Daphnia magna'ya göre istatistiksel olarak önemli düzeyde daha hassas olduğu ortaya konulmuştur. Bu nedenle D. magna'nın neonikotinoitlere karşı duyarsız olabileceği, ancak $G$. pulex' in son derece duyarlı olduğunu tespit etmişlerdir. Buradan yola çıkarak ekotoksikolojik çalışmalar için önemli bir biyogösterge tür olarak Gammarus türlerinin oldukça hassas türler olduğu düşünülebilir.

\section{SONUÇ}

Sonuç olarak ortalama lethal konsantrasyon hem sucul kirlilikle ilgili hızlı bir yanıt elde etmek

\section{KAYNAKLAR}

Anderson RL, 1982. Toxicity of fenvalerate and permethrin to several nontarget aquatic invertebrates. Environmental Entomology 11: 1251-1257

Ashauer R, Boxall AB, Brown CD, 2007. New ecotoxicological model to simulate survival of aquatic invertebrates after exposure to fluctuating and sequential pulses of pesticides. Environmental Science \& Technology 41: 1480-1486.

Ashauer R, Hintermeister, A, Potthoff E, Escher, BI, 2011. Acute toxicity of organic chemicals to Gammarus pulex correlates with sensitivity of Daphnia magna across most modes of action. Aquatic Toxicology 103: 38-45.

Ashauer R, Caravatti I, Hintermeister A, Escher BI, 2010. Bioaccumulation kinetics of organic xenobiotic pollutants in the freshwater invertebrate Gammarus pulex modeled with prediction intervals. Environmental Toxicology and Chemistry 29: 1625-1636.

Beketov MA, Liess M, 2008. Acute and delayed effects of the neonicotinoid insecticide thiacloprid on seven freshwater arthropods. Environmental Toxicology and Chemistry 27: 461-470.

Beketov MA, Liess M, 2008. Potential of 11 Pesticides to Initiate Downstream Drift of Stream Macroinvertebrates. Archives of Environmental Contamination and Toxicology 55: 247-253.

Blacquiere T, Smagghe G, Van Gestel CA, Mommaerts V, 2012. Neonicotinoids in bees: a review on concentrations, sideeffects and risk assessment. Ecotoxicology, 21: 973-992.

Cold A, Forbes, VE, 2004. Consequences of a short pulse of pesticide exposure for survival and reproduction of Gammarus pulex. Aquatic Toxicology 67: 287-299.

Demirci O, Guven K, Asma D, Ogut S, Ugurlu P, 2015. The effects of atrazine and thiamethoxam at sublethal concentrations on some antioxidant enzymes of Gammarus kischineffensis. Toxicology Letters 2: 131 . için oldukça verimli testlerdir. Üstelik biyokimyasal cevaplar için önbilgi sağladığı için oldukça yararlıdır. Ayrıca Gammarus türleri gibi biyogösterge olan türler bu tür testler için hem omurgasız hayvanlar oldukları için (3R prensibi) hem de çevresel kirleticilere oldukça duyarlı oldukları için sucul toksikoloji çalışmalarında tercih edilebilir.

$\mathrm{AB}$ komisyonu tarafindan yasaklanan imidakloprit ile yasaklı olmayan asetamipritin $\mathrm{LC}_{50}$ değerleri karşılaştırıldığında asetamipritin daha yüksek akut toksisiteye neden tespit edilmiştir (Ojeu, 2013; US EPA, 2017). Bununla birlikte pestisitlerin ticari ve analitik standart halinde bulunmasının da akut toksisite üzerinde önemli düzeyde etkiye sahip olduğu ortaya konulmuştur.

Demirci O, Guven K, Asma D, Ogut S, Ugurlu P, 2018. Effects of endosulfan, thiamethoxam, and indoxacarb in combination with atrazine on multi-biomarkers in Gammarus kischineffensis. Ecotoxicology and Environmental Safety, 147: 749-758.

Decourtye A., Devillers J, 2010. Ecotoxicity of neonicotinoid insecticides to bees Insect nicotinic acetylcholine receptors, Springer, 85-95 p.

DeLorenzo M, Taylor L, Lund S, Pennington P, Strozier E, Fulton M 2002. Toxicity and bioconcentration potential of the agricultural pesticide endosulfan in phytoplankton and zooplankton. Archives of Environmental Contamination and Toxicology. 42: 173-181

Dietrich JP, Van Gaest AL, Strickland SA Arkoosh MR, 2014. The impact of temperature stress and pesticide exposure on mortality and disease susceptibility of endangered Pacific salmon. Chemosphere 108: 353-359.

Englert D, Zubrod, JP, Link M, Mertins S, Schulz R, Bundschuh M, 2017. Does Waterborne Exposure Explain Effects Caused by Neonicotinoid-Contaminated Plant Material in Aquatic Systems? Environmental Science \& Technology 51: 5793-5802.

Federation WE, Association A, 2005. Standard methods for the examination of water and wastewater. American Public Health Association (APHA): Washington, DC, USA.

Fisher S, 1991. Changes in the toxicity of three pesticides as a function of environmental $\mathrm{pH}$ and temperature. Bulletin of environmental contamination and toxicology 46: 197-202.

Folt, C, Chen, C, Moore, M, Burnaford, J, 1999. Synergism and antagonism among multiple stressors. Limnology and oceanography, 44: 864-877.

Gerhardt A, Kienle C, Allan IJ, Greenwood R, Guigues N, Fouillac AM, Mills GA, Gonzalez C, 2007. Biomonitoring with Gammarus pulex at the Meuse (NL), Aller (GER) and Rhine (F) rivers with the online Multispecies Freshwater Biomonitor ${ }^{\circledR}$. Journal of Environmental Monitoring 9: 979-985. 
Hodson PV, Dixon DG, Kaiser KL, 1988. Estimating the acute toxicity of waterborne chemicals in trout from measurements of median lethal dose and the octanol-water partition coefficient. Environmental toxicology and Chemistry. 7: 443454

Hoffmann EJ, Middleton SM, Wise JC, 2008. Ovicidal activity of organophosphate, oxadiazine, neonicotinoid and insect growth regulator chemistries on northern strain plum curculio, Conotrachelus nenuphar. Journal of Insect Science 8:1-6

Iwasa T, Motoyama N, Ambrose JT, Roe RM, 2004. Mechanism for the differential toxicity of neonicotinoid insecticides in the honey bee. Apis mellifera. Crop Protection 23: 371-378.

Johnson WW, Finley MT, 1980. Handbook of acute toxicity of chemicals to fish and aquatic invertebrates: Summaries of toxicity tests conducted at Columbia National Fisheries Research Laboratory, 1965-78, US Fish and Wildlife Service.

Kocaman AY, Topaktaş M, 2007. In vitro evaluation of the genotoxicity of acetamiprid in human peripheral blood lymphocytes. Environmental and Molecular Mutagenesis 48: 483-490.

Kunz PY, Kienle C, Gerhardt A, 2010. Gammarus spp. in aquatic ecotoxicology and water quality assessment: toward integrated multilevel tests. Reviews of Environmental Contamination and Toxicology Volume 205: 1-76.

Lukančič S, Žibrat U, Mezek T, Jerebic A, Simčič T, Brancelj A, 2010. A new method for early assessment of effects of exposing two non-target crustacean species, Asellus aquaticus and Gammarus fossarum, to pesticides, a laboratory study. Toxicology and industrial health 26: 217-228.

Maltby L,. Clayton SA, Wood RM, McLoughlin N, 2002. Evaluation of the Gammarus pulex in situ feeding assay as a biomonitor of water quality: robustness, responsiveness, and relevance. Environmental Toxicology and Chemistry 21: 361-368.

Millar NS, Denholm I, 2007. Nicotinic acetylcholine receptors: targets for commercially important insecticides. Invertebrate Neuroscience 7: 53-66.

Mishchuk OV, Stoliar OB, 2008. The effect of pesticide acetamiprid on biochemical markers in tissues of fresh water bivalve mussels Anodonta cygnea L. (Unionidae). Ukrains'kyi Biokhimichnyi Zhurnal 80: 117-124.

Mullins J, 1993. Imidacloprid: a new nitroguanidine insecticide. ACS Publications 13: 183-198

Ojeu 2013. Commission Implementing Regulation (EU) No 485/2013 of 24 May 2013 amending Implementing Regulation (EU) No 540/2011, as regards the conditions of approval of the active substances clothianidin, thiamethoxam and imidacloprid, and prohibiting the use and sale of seeds treated with plant protection products containing those active substances. Ojeu 139: 12-14.

Pereira JL, Antunes SC, Castro BB, Marques CR, Gonçalves, AM, Gonçalves, F, Pereira R, 2009. Toxicity evaluation of three pesticides on non-target aquatic and soil organisms: commercial formulation versus active ingredient. Ecotoxicology 18: 455463.
Poulton M, Pascoe D, 1990. Disruption of precopula in Gammarus pulex (L) development of a behavioural bioassay for evaluating pollutant and parasite induced stress. Chemosphere 20: 403-415.

Raj SJ, Joseph B, 2015. Impact of Acetamiprid Toxicity on Lactate Dehydrogenase in Some Tissues of the Fish Oreochromis mossambicus. International Journal of Zoological Research 11: 112-115.

Roessink I, Merga LB, Zweers HJ, Van den Brink PJ, 2013. The neonicotinoid imidacloprid shows high chronic toxicity to mayfly nymphs. Environmental Toxicology and Chemistry 32: 1096-1100.

Sánchez BF, Goka K, Hayasaka D, 2016. Contamination of the aquatic environment with neonicotinoids and its implication for ecosystems. Frontiers in Environmental Science 4: 1-14.

Siddiqui MS, Wanule DD, 2010. Acetamiprid induced changes in total leucocytes and erythrocytes count in a freshwater fish, Channa Punctatus (bloch) The Bioscan 5: 163 - 164.

Song MY, Stark JD, Brown JJ, 1997. Comparative toxicity of four insecticides, including imidacloprid and tebufenozide, to four aquatic arthropods. Environmental Toxicology and Chemistry 16: 2494-2500.

Tomizawa M, Casida JE, 2003. Selective toxicity of neonicotinoids attributable to specificity of insect and mammalian nicotinic receptors. Annual Review Entomology 48: 339-364.

Uğurlu P, Ünlü E, Satar Eİ, 2015. The toxicological effects of thiamethoxam on Gammarus kischineffensis (Schellenberg 1937) (Crustacea: Amphipoda). Environmental Toxicology and Pharmacology 39: 720-726.

US EPA 2017. https://www3.epa.gov/pesticides/endanger/litstatus/ effects/redleg-frog/naled/appendix-i.pdf. Erişim tarihi: 30.11.2017.

EU Commision 2018. https://ec.europa.eu/food/plant/ pesticides/approval_active_substances/-approval_renewal/ neonicotinoids_en Erişim tarihi: 22.02.2018.

Van den Brink PJ, Van Smeden JM, Bekele RS, Dierick W, De Gelder DM, Noteboom M, Roessink I, 2016. Acute and chronic toxicity of neonicotinoids to nymphs of a mayfly species and some notes on seasonal differences. Environmental Toxicology and Chemistry 35: 128-133.

Van Leeuwen CJ, Vermeire TG, 2007. Risk assessment of chemicals: an introduction, Springer Science \& Business Media, Netherlands

Watts MM, Pascoe D, Carroll K, 2001. Survival and precopulatory behaviour of Gammarus pulex (L.) exposed to two xenoestrogens. Water Research 35: 2347-2352.

Whitehorn PR, O'connor S, Wackers FL, Goulson D, 2012. Neonicotinoid pesticide reduces bumble bee colony growth and queen production. Science 1215025

Yamamoto I, Casida JE, 1999. Nicotinoid Insecticides and the Nicotinic Acetylcholine Receptor A Novel Insecticide, Acetamiprid. Springer, Tokyo 